\title{
EL EJERCICIO DE LAS COMPETENCIAS ECONÓMICAS EN LA UNIÓN EUROPEA: ¿ES POSIBLE OTRA POLÍTICA?
}

\author{
Daniel Guerra Sesma
}

doi: 10.18543/ed-64(2)-2016pp43-65

\begin{abstract}
SUMARIO. 1. INTRODUCCIÓN. 2. EL MARCO JURÍDICO DE LA INTEGRACIÓN ECONÓMICA. 3. El CASO DE GRECIA: SOBERANÍA NACIONAL VS. INTEGRACIÓN EUROPEA. 4. LA TRANSFORMACIÓN DEL ESTADO-NACIÓN: ¿HAY OPCIÓN? 5. ESCOLIO. 6. CONCLUSIONES.
\end{abstract}

\section{INTRODUCCIÓN ${ }^{1}$}

En Derecho Internacional Público definimos a la Unión Europea como una organización internacional de integración. Las organizaciones internacionales (en adelante, OO.II.) son intergubernamentales en el sentido de que están formadas por Estados y sus gobiernos son, como responsables de su política exterior, los que normalmente actúan en ellas. Sin embargo, la intergubernamentabilidad es más clara en las OO.II. de cooperación, donde las decisiones son adoptadas básicamente por los Estados ${ }^{2}$. Las OO.II. de integración, en cambio, tienen una parte de las competencias cedida por éstos y unos órganos propios que adoptan decisiones autónomamente, así como un

${ }^{1}$ Agradezco las sugerencias realizadas por los profesores de la Universidad de Sevi1la Marycruz Arcos y Luis Palma.

2 En el caso de la UE, hay que citar los límites constitucionales establecidos por el Tribunal alemán de Karlsruhe a partir de la famosa sentencia BVerfGE 89, 155, de 12 de octubre de 1993, que mantiene la tradicional doctrina de la supremacía constitucional. 
derecho interno que les es más o menos vinculante. El ejemplo paradigmático que se suele citar es el de la UE, aunque se pueden mencionar también, sin alcanzar el mismo nivel de integración, el MERCOSUR y la Organización Mundial de la Salud.

El proceso de integración europea es lento y complejo, y responde a la lógica de la Declaración Schumman (1950) de ir paso a paso, asumiendo por atribución competencias materiales para luego ir construyendo el marco institucional de referencia. El proceso ha tenido dos fases distintas: una primera, entre el Tratado de París de 1951 que crea la Comunidad Europea del Carbón y el Acero (CECA) y el Acta Única Europea de 1986, y una segunda que llega hasta el Tratado de Lisboa (2007), vigente desde el 1 de diciembre de 2009.

La primera fase partió de la idea de Europa como un espacio de paz y de seguridad común después de dos guerras mundiales que se produjeron, sobre todo, por la ancestral enemistad franco-alemana. La producción conjunta de carbón y acero por estos dos países, elementos necesarios para la fabricación de armas, alejaba la posibilidad de nuevas tensiones entre ellos. A ello hay que añadir el poso que dejó la cooperación económica de los países europeos para gestionar la ayuda del Plan Marshall (1947-48), lo que se tradujo en la creación de la Organización Europea de Cooperación Económica (OECE, 1948), que se transforma en 1965 en la OCDE. Esta cooperación marcó la primera fase de la construcción europea, basada en la construcción de un marco económico para la producción conjunta de recursos mineros, industriales y agrícolas, así como en la supresión de barreras comerciales, aduaneras y de circulación de bienes, personas y servicios entre los Estados miembros.

En efecto, la preocupación inicial de los impulsores de la integración europea fue su vertiente económica. A partir del AUE de 1986, y sobre todo de la cumbre de Maastricht en 1992, se construye un complejo marco institucional que acoge las competencias económicas e intenta dar legitimidad formal a la toma de decisiones sobre las mismas. Los tres pilares de las Comunidades Europeas - la CE, la cooperación en asuntos de Justicia e Interior, y la Política Exterior y de Seguridad Común (PESC)- se irán fundiendo en una única organización internacional. Sin embargo, esta construcción política ha tenido diversos problemas. De una parte, la opinión pública no acepta de buen grado esa prioridad económica en el proceso de integración, y no percibe claramente dónde reside la toma de decisiones y a quién se ha de reclamar la responsabilidad política correspondiente - la accountability(Torreblanca, 2014; Rodríguez Aguilera, 2015). En una palabra: el marco institucional se percibe como difuso, complejo y artificial, como si se diseñara para justificar los objetivos económicos primarios, convirtiéndose en lo que Enzensberger denomina «el gentil monstruo de Bruselas» 
(Enzensberger, 2014). Por otra parte, la integración europea no responde claramente a un proceso clásico de federación de territorios previamente soberanos, lo que sería más fácilmente comprensible, sino que alterna elementos federales con otros intergubernamentales. En mi opinión, el tipo de constitución europea va muy ligado al grado de democratización del mismo.

Hay que partir de la base de que los Estados europeos no son las trece colonias británicas que constituyeron los Estados Unidos de América. No es probable que naciones tan antiguas y diferentes como Alemania, Francia, Italia, España, Suecia o el Reino Unido, con relaciones históricas pacíficas unas veces y conflictivas otras, lleguen a constituir un Estado federal europeo, pues eso supondría su disolución como Estados y no parece que eso vaya a ocurrir. Pero mientras tanto es cierto que van atribuyendo, a través de los diversos tratados constitutivos, competencias a la Unión, y no es menos cierto que, de acuerdo con las tesis de Schumman y Monnet, siguen cediendo funciones desde el punto de vista material, sobre todo en el terreno económico. El Tratado Constitucional de 2004, rechazado por los pueblos holandés y francés en referéndum, fue un intento de definir el marco político para el proceso de integración que se estaba viviendo. Sin embargo, ese intento reprodujo en parte las características que la opinión pública europea, en general, apreciaban como negativas desde un punto de vista democrático y de clarificación institucional, lo que se demostró en los referéndums citados, en los que también intervinieron factores de política interna. La propia denominación de «Tratado constitucional» dio pistas de la confusión del proceso, pues a la vista de una parte de la doctrina constitucional y sobre todo internacionalista resultaba un oxímoron desde el momento en que un Tratado es un acuerdo entre Estados ( $u$ organizaciones internacionales) mientras que una Constitución es un acuerdo entre ciudadanos de un país, por lo que pertenecen a categorías jurídicas distintas. La composición de la Convención redactora y la complejidad del texto propuesto desalentó la posibilidad de un auténtico proceso constituyente de tipo federal, con un marco institucional definido, un esquema competencial claro y unas responsabilidades políticas bien determinadas. A pesar de los avances que suponía, la mayoría de los electorados francés y holandés, escépticos o desconocedores de su contenido, lo rechazaron precisamente por querer más Europa y ante todo otra Europa, sobre la que no hay tampoco un suficiente consenso en su definición.

La integración política es más exigible aún en el contexto geopolítico actual dominado por la globalización y por tres grandes Estados de magnitudes y vocación imperiales: EE.UU., Rusia y China (Beck, 2000; Held \& McGrew, 2003). Los tres más poderosos, aunque por razones distintas: 
- EE.UU. mantiene la fuerza militar más importante, aunque sus contradicciones en Irak, Afganistán y en su lucha contra el terrorismo yihadista dan pistas de que ello ya no garantiza el predominio en el mundo como antes. Sin embargo, EE.UU. ha reflotado su economía antes que Europa, sobre todo porque su economía capitalista es mucho más abierta y con más capacidad de recuperación, y por la actuación en la crisis financiera de una Reserva Federal de la que Europa aún carece. Sin llegar al nivel de concentración del poder político de Rusia y China, y con una legitimidad democrática, no se debe minusvalorar el hecho de que las políticas económica y exterior están dirigidas por un gobierno presidencialista.

- Rusia configura una creciente concentración de poder en el aparato controlado por Vladimir Putin. Concentración de poder político, que raya en la intolerancia de una oposición abierta, y de poder económico en la posesión de enormes fuentes de hidrocarburos de la que Europa es claramente dependiente.

- China une a la concentración del poder político en manos del Partido Comunista una evolución económica de apertura liberal y un creciente dominio del comercio mundial acompañado de fuertes reservas financieras con las que opera libremente en África y América Latina y adquiere cada vez más deuda pública de más Estados.

\section{EL MARCO JURÍDICO DE LA INTEGRACIÓN ECONÓMICA.}

Para entender bien el grado de integración económica y la relación con las soberanías nacionales, debemos estudiar el marco normativo que la regula, para lo que consideramos los siguientes tratados:

- el Tratado de la Unión Europea (TUE), de 1992.

- el Tratado de Funcionamiento de la Unión Europea (TFUE), de 2007.

- el Pacto de Estabilidad y Crecimiento (PEC), de 1997.

- el Tratado de Estabilidad, Coordinación y Gobernanza (TECG), de 2012.

- el Mecanismo Europeo de Estabilidad (MEDE), de 2013. ${ }^{3}$

3 TUE: $<$ http://www.boe.es/doue/2010/083/Z00013-00046.pdf>

TFUE: <http://www.boe.es/doue/2010/083/Z00047-00199.pdf>

PEC: <http://eur-lex.europa.eu/legal-content/ES/TXT/HTML/?uri=URISERV:12502 $1 \&$ from $=\mathrm{ES}>$

TECG: <http://www.boe.es/boe/dias/2013/02/02/pdfs/BOE-A-2013-1118.pdf>

MEDE: <http://boe.es/boe/dias/2012/10/04/pdfs/BOE-A-2012-12378.pdf> 
Podemos decir que la UE, en este momento, avanza hacia un modelo de confederación implícita con un importante nivel de integración política y económica. Implícita porque no se define así en los tratados, y que sigue avanzando, a su manera, aplicando mecanismos federales de coordinación pero sin llegar a un proceso constituyente de tipo federal (Ruipérez, 2000) . Esto se ha puesto de manifiesto en la crisis con Grecia, en la que se dirimen dos cuestiones:

- una, el concepto de soberanía dentro de la UE;

- dos, la política económica aplicable en la UE.

Siendo dos cuestiones distintas, están íntimamente relacionadas. En efecto, en Grecia no sólo ha ganado las últimas elecciones una coalición que reclama más soberanía nacional (como también en Polonia, pero desde un signo político opuesto), sino que además la quiere para aplicar una política económica distinta a la dominante en la Unión. La respuesta de ésta ha sido contundente al dejar claro que un Estado miembro no puede aplicar unilateralmente una política económica que no haya sido coordinada con los demás Estados en el Consejo, sobre todo cuando debe recibir ayudas de la Unión. Esto es lo que Wolfang Schäuble, ministro de Finanzas alemán, le dijo a su homólogo griego, Yanis Varoufakis, tras su primera entrevista: «Respeto los resultados electorales. El problema es cuando se hacen promesas que no son realistas a costa de terceros».$^{5}$

El artículo 3 del Tratado de la Unión Europea (TUE) marca como un objetivo fundamental de la Unión el mercado interior:

La Unión establecerá un mercado interior. Obrará en pro del desarrollo sostenible de Europa basado en un crecimiento económico equilibrado y en la estabilidad de los precios, en una economía social de mercado altamente competitiva, tendente al pleno empleo y al progreso social, y en un nivel elevado de protección y mejora de la calidad del medio ambiente. Asimismo, promoverá el progreso científico y técnico.

El artículo 5 del Tratado de Funcionamiento de la Unión Europea (TFUE) consagra el principio de coordinación de las políticas económicas de los EE.MM. en el Consejo, que aplicará medidas para garantizarla y definirá las orientaciones de la misma:

${ }^{4}$ En sus propios términos, y citando a La Pérgola, la Unión Europea no es un Bundestaat (Estado federal) ni una Staatenbund (Federación de Estados), sino un término medio que el TC alemán llama Staatenverbund (RUIPÉREZ, 2000: 77).

5 El País, 5.02.15: <http://internacional.elpais.com/internacional/2015/02/05/actualidad/1423142092_538144.html> 
Los Estados miembros coordinarán sus políticas económicas en el seno de la Unión. Con este fin, el Consejo adoptará medidas, en particular las orientaciones generales de dichas políticas.

Se aplicarán disposiciones particulares a los Estados miembros cuya moneda es el euro.

La Unión tomará medidas para garantizar la coordinación de las políticas de empleo de los Estados miembros, en particular definiendo las orientaciones de dichas políticas.

Éstas se concretan en el Capítulo 1 del Título VIII (antes VII del TCE), en cuyo artículo 121 se define la política económica de los Estados como «una cuestión de interés común». Dicha política, bajo la coordinación del Consejo, se considera necesaria para alcanzar los objetivos del art. 3 TUE y 119-120 TFUE: mercado interior, economía de mercado abierta y libre competencia. Esto es más evidente en la zona euro, donde la política monetaria es igualmente común.

Así, el artículo 119 define la política económica aplicable en la UE como «la estrecha coordinación de las políticas económicas de los Estados miembros, en el mercado interior y en la definición de objetivos comunes, y que se llevará a cabo de conformidad con el respeto al principio de una economía de mercado abierta y de libre competencia».

Los arts. 121.2 y 136.1 asignan al Consejo la elaboración, a iniciativa de la Comisión, de las «orientaciones generales para las políticas económicas de los Estados miembros y de la Unión», así como las funciones de coordinación, supervisión y control, recogidas en el citado 136.1 y también en los arts. 121.3, 121.4.

El art. 126 establece que «los Estados miembros evitarán déficits públicos excesivos», y deposita la función de control en la Comisión, que procurará la «observancia de la disciplina presupuestaria» atendiendo a la relación entre déficit público y PIB (3\%) o entre deuda pública y PIB (60\%, según el Protocolo 12 del TUE). En caso de que un Estado incumpla el nivel máximo de déficit establecido, la Comisión traslada la función de control al Consejo, que puede establecer las siguientes medidas (art. 121.11):

- exigir al Estado miembro de que se trate que publique una información adicional, que el Consejo deberá especificar, antes de emitir obligaciones y valores,

- recomendar al BEI que reconsidere su política de préstamos respecto al Estado miembro en cuestión,

- exigir que el Estado miembro de que se trate efectúe ante la Unión un depósito sin devengo de intereses por un importe apropiado, hasta que el Consejo considere que se ha corregido el déficit excesivo,

- imponer multas de una magnitud apropiada. 
El citado Protocolo 12 del TUE, en su artículo 3, imputa a los Gobiernos centrales la responsabilidad del déficit estatal excesivo y establece que «los Estados miembros garantizarán que los procedimientos nacionales en materia presupuestaria les permitan atender, en dicho ámbito, a sus obligaciones derivadas de los Tratados.», y les obliga a comunicar a la Comisión sus déficits previstos y reales y el nivel de su deuda.

El PEC ya preveía este mecanismo de supervisión y sanción para los Estados que pasaran el $3 \%$ de déficit público, a no ser que se debiera a circunstancias inhabituales independientes de la voluntad del Estado o a una recesión económica grave. De hecho, la Comisión envió una comunicación al Consejo advirtiendo que «fijar objetivos idénticos para todos los países en una Unión con 25 Estados miembros no es conveniente desde un punto de vista económico», y que «la existencia de plazos idénticos para todos los países para corregir el déficit excesivo presenta límites fundamentales ya que no permite tener en cuenta las diferencias económicas entre países, como las evoluciones cíclicas y los niveles de endeudamiento». Estas recomendaciones sólo fueron parcialmente consideradas por el ECOFIN el 20 de marzo de 2005 , en un documento en el que se añadía que «el aumento de la coordinación de las políticas fiscales debe hacerse respetando el principio de subsidiariedad del Tratado y las prerrogativas de los Gobiernos nacionales para determinar sus políticas estructurales y presupuestarias», pero concluyendo, tras esta concesión retórica, que «los Estados deben cumplir las recomendaciones del Consejo». ${ }^{6}$

En todo caso, el Consejo podía y puede valorar las circunstancias del déficit de cada Estado para decidir la sanción o bien prolongar los plazos de cumplimiento, de acuerdo con el art. 126.6 TFUE y el 3b del TECG, aplicándose recientemente en el caso de Francia. Este tratado puede considerarse como una actualización del Pacto de Estabilidad de 1997 en un sentido más restrictivo:

${ }^{6}$ Informe del Consejo ECOFIN, 20 Marzo 2005 «Mejorar la aplicación del Pacto de Estabilidad y Crecimiento»: <http://register.consilium.eu.int/pdf/es/05/st07/st07619re01.es05.pdf>.

Este informe se tradujo en sendos reglamentos de modificación del PEC,

- el REGLAMENTO (CE) N. ${ }^{\circ}$ 1055/2005 DEL CONSEJO de 27 de junio de 2005 por el que se modifica el Reglamento (CE) n. ${ }^{\circ}$ 1466/97 del Consejo relativo al refuerzo de la supervisión de las situaciones presupuestarias y a la supervisión y coordinación de las políticas económicas: $<$ http://eur-lex.europa.eu/legal-content/ $\mathrm{ES} / \mathrm{TXT} / \mathrm{PDF} /$ ?uri=CELEX:32005R1055\& from $=\mathrm{EN}>$

- el REGLAMENTO (CE) N. ${ }^{\circ}$ 1056/2005 DEL CONSEJO de 27 de junio de 2005 por el que se modifica el Reglamento (CE) n. ${ }^{\circ}$ 1467/97 relativo a la aceleración y clarificación del procedimiento de déficit excesivo: $<$ http://eur-lex.europa.eu/legalcontent/ES/TXT/PDF/?uri=CELEX:32005R1056\&from=EN> 
- Exige la inclusión de sus normas en el derecho interno de cada Estado, preferentemente por vía constitucional (art. 1.2),

- crea la Cumbre del Euro (regiones semestrales de Jefes de Estado y de Gobierno de la Zona euro)

- estrecha la coordinación de las políticas económicas entre los Estados miembros,

- endurece el proceso sancionador contra el Estado que no cumpla el objetivo de déficit público ( $3 \%$ del PIB), al poder ser denunciado ante el Tribunal de Justicia (art. 8), y mantiene el compromiso de la deuda pública inferior al $60 \%$ del PIB en veinte años como máximo.

- sitúa el límite de déficit estructural en el $0^{\prime} 5 \%$ y del $1 \%$ en los países que tengan una deuda inferior al $60 \%$ del PIB.

A este control por parte del Consejo hay que añadir la puesta en marcha del Semestre Europeo en la zona euro a partir de 2013, a través del cual la Comisión puede recomendar y supervisar, durante los seis primeros meses del año, la aplicación de los criterios de convergencia. Asimismo, la Comisión puede supervisar los proyectos presupuestarios de los EE.MM. antes de su aprobación nacional.

Este nivel de integración no se ha dado en otras materias, y no sólo en la política. Si bien los EE.MM. han cedido su soberanía económica, no han hecho lo mismo con la política exterior, materia en la que se reservan sus propias competencias nacionales, lo que limita la PESC como política común. Las relaciones exteriores diplomáticas y las cuestiones relativas a la nacionalidad son demasiado sensibles para los Estados como para cederlas siquiera a una O.I. de integración. Que un Estado renuncia a otorgar la nacionalidad supondría renunciar a su propia nacionalidad, y por lo tanto a su propia existencia. Otras políticas comunes, como la de agricultura, pesca, transportes y consumo, han alcanzado también un alto grado de integración. Pero resulta curioso que la política económica, que define igualmente la soberanía nacional de los Estados, no haya tenido ese miramiento por su parte en favor de un contexto superior marcado por unos principios ideológicamente sesgados.

\section{EL CASO DE GRECIA: SOBERANÍA NACIONAL VS. INTEGRACIÓN EUROPEA}

Así pues, los tratados dejan bien claro que las políticas económicas de los Estados ya no son autónomas, sino que deben estar coordinadas y supervisadas por el Consejo y cumpliendo además unos principios liberales, de acuerdo con los objetivos de la Unión. La soberanía nacional invocada por Syriza ha desaparecido en el terreno económico porque su ejercicio se ha 
traspasado al ámbito de la Unión. Pero no lo ha hecho a alguno de los órganos centrales que representan a la ciudadanía europea -como el Parlamento-, sino a otro órgano, el Consejo, compuesto por los gobiernos de los EE.MM. (por más que sí se ha traspasado parcialmente a la Comisión). Es decir, la política económica de los Estados sigue básicamente en manos de los mismos, pero ya no de forma aislada sino coordinada, porque su aplicación requiere el acuerdo conjunto de todos.

Realmente, las competencias económicas de los Estados se han difuminado entre el Consejo y el mercado interior. Cuando un Estado ya no puede intervenir en la economía nacional porque su competencia la ha cedido a la UE (por ejemplo, para aprobar ayudas públicas a un sector productivo), no se plantea un conflicto competencial entre el gobierno del Estado y un órgano equivalente superior, sino entre el Estado y la Unión como sistema institucional que consagra el mercado interior y la libre competencia. Esas ayudas ya no las podrá otorgar el Estado, pero no porque las tiene que dar un órgano europeo competente, sino porque en la UE ya no se puede dar ese tipo de ayudas ${ }^{7}$. Luego no es un problema de abrogación de las competencias estatales por parte de la Unión, sino un conflicto entre el Estado nacional y el mercado interior europeo: en una palabra, entre Estado y mercado interior. La limitación de competencias económicas de los Estados miembros no significa menos Estado y más Unión, sino menos Estado y más mercado.

La política económica europea es, pues, la acordada por los Estados en el Consejo, no la aplicada por un gobierno que no existe, lo que sería más lógico en un proceso constituyente en el que hubiera un gobierno ejecutivo (que es lo que podría ser la Comisión). Así, la integración europea avanza con la aplicación de mecanismos más propios de un federalismo intergubernamental que de un federalismo orgánico o, en términos de Habermas, federalismo ejecutivo o tecnocrático (Habermas, 2012). Las decisiones importantes ya no las toman los Estados individualmente, sino la Unión, pero dentro de ésta siguen siendo los Estados las que las acuerdan en el seno del Consejo, del Consejo Europeo y del Eurogrupo. El ámbito de decisión interestatal prima sobre el central, representado por la Comisión y el Parlamento Europeo. La Comisión no es un Gobierno ejecutivo, sino un órgano regulador con competencias, como hemos visto, limitadas. Por su parte, el Parlamento carece aún de las funciones legislativas propias de un parlamento soberano porque no hay soberanía europea, sino sólo ciudadanía europea.

Por consiguiente, los avances en la integración económica se están dando por la mancomunidad de decisiones entre los Estados, más que por la consolidación de los órganos centrales de la Unión. Y con un sesgo determinado:

${ }^{7}$ Las ayudas estatales pueden alterar la competencia del mercado interior, por lo que sólo se admiten las indicadas en el artículo 107 del TFUE. 
control del déficit público y mercado interior libre. El PEC, el TECG y el MEDE han supuesto sin duda pasos importantes en dicha integración, pero es limitada porque no vienen acompañadas de las correspondientes uniones fiscal, bancaria, laboral y social. La integración política, como ya se ha indicado, va más lenta, aunque un paso federal importante ha sido el ejercicio de las competencias exclusivas de la Unión (art. 3 TFUE) y de las compartidas con los EE.MM. que han pasado el examen de subsidiariedad (arts. 4 TFUE y 5.3 TUE).

Este proceso hace que muchos ciudadanos no tengan una idea clara de quién decide qué en Europa. Pueden preguntarse: «si los Estados nacionales ya no deciden las políticas económicas, ¿quién lo hace?». La respuesta, como se ha dicho, está en los Tratados: decide el Consejo, es decir, los mismos Estados pero de forma acordada. Desde un planteamiento típico de Estadonación, no es fácil asimilar el hecho de que las competencias económicas estatales no se hayan traspasado a otros órganos unitarios con una responsabilidad concreta. El paso de las mismas al Consejo se puede ver como un traspaso competencial difuso, como si esa competencia anteriormente estatal se perdiera por el camino porque no es asumida por la Comisión. Así, es cierto que el mecanismo de acuerdo entre Estados es un avance, pero lo sería más si la política económica europea la asumiera un órgano central como una Comisión con funciones más ejecutivas que regulatorias. Es decir, un órgano claramente perceptible y al que se le pudiera imputar la responsabilidad política correspondiente de manera más clara. Un paso decidido en esta línea sería que el BCE se convirtiera en un auténtico banco público europeo con capacidad legal, - no excepcional y limitada como ahora- para adquirir directamente deuda pública de los Estados miembros. Nos encontramos ante la perversión que supone la compra indirecta a través de la banca privada, que adquiere créditos del BCE a interés cero para adquirir la deuda de los Estados, a los que luego exige intereses del 4 o el $5 \%$.

A esa sensación contribuye también el que en el seno del Consejo sean Alemania y otros Estados del norte (apoyados por algunos disciplinados alumnos del Sur), los que intentan imponer sus tesis económicas basadas en el ajuste de las cuentas públicas por encima del estímulo de la demanda y de un mayor intervencionismo estatal. Sin embargo, determinadas medidas y sucesos recientes pueden limitar ese dominio alemán:

1. ${ }^{\circ}$ La presentación del Fondo Europeo de Inversiones Estratégicas (conocido como «Plan Juncker» ${ }^{8}$ ) como un estímulo a la demanda mediante la promoción de nuevas inversiones públicas. Una vez descartada la

$8<$ http://eur-lex.europa.eu/legal-content/ES/TXT/PDF/?uri=CELEX:52014DC0903 \&from $=$ FR $>$ 
consignación de las aportaciones nacionales al Plan como déficit de los Estados, hay que consignar prudencia sobre algunos aspectos diseñados en el Plan pero que el tiempo nos dirá cuál es su evolución:

- por una parte, el Plan establece que un Comité de Inversiones, propuesto por el Consejo ${ }^{9}$, evaluará la idoneidad de los proyectos inscritos en un Directorio. Es importante que éstos no se vean afectados ni por intereses territoriales de los inversores nacionales ni de los privados;

- la respuesta de la inversión privada al Fondo de Inversiones Estratégicas (FEIE), que ha de alcanzar los 315.000 millones de euros: habrá que ver si las aportaciones de los Estados (de momento sólo Francia, Alemania, Italia con 8.000 millones cada uno, y España con 1.500), y las garantías del BCE y del BEI son suficientes para estimular dicha inversión.

2. ${ }^{\circ}$ La decisión del BCE de adquirir títulos de deuda pública de los EE.MM. en el mercado secundario (Programa OMT) es un paso para aligerar la presión que los acreedores privados ejercen sobre ellos. Hay que destacar en esta decisión el informe del abogado general del TJUE, el español Pedro Cruz Villalón, a instancias de una cuestión prejudicial presentada por el Tribunal Constitucional alemán ${ }^{10}$. Cruz Villalón señaló que dicha adquisición, en determinadas condiciones, no extralimita las competencias atribuidas al $\mathrm{BCE}$ relacionadas con la política monetaria, por lo que no implica su intrusión en la política económica del Consejo. Esta doctrina ha sido confirmada por el TJUE en su sentencia del 16 de junio. Se trata, en todo caso, de una medida no convencional que persigue la reducción de los intereses de la deuda pública estatal, no la financiación de dicha deuda, y no rebasa el principio de proporcionalidad competencial. ${ }^{11}$

3. ${ }^{\circ}$ El Mecanismo Único de Supervisión (MUS): la propuesta de que el BCE pueda estar presente en los Consejos de Administración de los Bancos para una mejor supervisión ha sido previamente negociada con Alemania. ${ }^{12}$

\footnotetext{
${ }_{9}$ En la propuesta de Reglamento de 5.03.15: < http://register.consilium.europa.eu/ doc/srv?l=ES\&f=ST \%206831 \%202015\%20INIT>

La propuesta de la Comisión, en $<$ http://eur-lex.europa.eu/legal-content/ES/TXT/PD F/?uri=CELEX:52014DC0903\&from $=$ FR $>$

$10<$ http://curia.europa.eu/jcms/upload/docs/application/pdf/2015-01/cp150002es. pdf $>$

$11<$ http://curia.europa.eu/jcms/upload/docs/application/pdf/2015-06/cp150070es. pdf $>$

$12<\mathrm{http}: / / w w w . b d e . e s /$ bde/es/areas/supervision/sup/Mecanismo_Unico_/
} 
4. ${ }^{\circ}$ El informe del Gobierno español sobre el futuro de la Unión económica, que se suma a las propuestas de Francia y Alemania, más moderadas. España propone pasos más decididos hacia la unión bancaria y fiscal, y a ampliar con más decisión las facultades del BCE.

$5 .^{\circ}$ En respuesta al eurodiputado asturiano Jonás Fernández, la Comisión ha reconocido que el art. 310 del TFUE no impide a la Unión emitir deuda pública, sino sólo para equilibrar el presupuesto ${ }^{13}$.

$6^{\circ}$ Avances en la aprobación de un Impuesto sobre Sociedades Europeo, paso importante para la unión fiscal.

Podríamos preguntarnos si el multilateralismo que se le exige a Grecia, ¿no lo está violando en parte también Alemania? Entre la ya citada declaración de Van Schaüble («El problema es cuando se hacen promesas que no son realistas a costa de terceros»), y esta de Mario Draghi: «no es admisible que la política económica de un país entrañe riesgos que rebasen las fronteras y afecte a los restantes socios de la unión monetaria» ${ }^{14}$, ¿hay mucha diferencia? Draghi también está denunciando aquí el unilateralismo de Alemania, el mismo que se exige a Grecia. ¿Cuál es la diferencia? Que Grecia lo pide, y Alemania lo impone. ¿Por qué? Porque puede.

Dos cosas lo favorecen: de acuerdo con su relato nacional, el que los alemanes ya iniciaran las reformas que ahora exigen a los demás, con la Agenda 2010 de Gerhard Schröder. Y en segundo lugar porque el gobierno de coalición entre los dos grandes partidos de centroderecha (CDU-CSU) y centroizquierda (SPD) aporta más legitimidad a la aplicación de sus políticas y una envidiable estabilidad tanto política como económica.

En todo caso, las cosas son como son y si Syriza y otros partidos como Podemos quieren cambiar la política económica europea, no pueden hacerlo ya unilateralmente desde cada Estado, sino que tendrán que cambiar la correlación de fuerzas dentro del Consejo y del Eurogrupo, intentando convencer a otros gobiernos de la necesidad del cambio. La suspensión por la UE del referéndum que Giorgios Papandreu propuso en 2011 para que el pueblo griego se manifestara sobre el segundo rescate acordado con Bruselas, dio buena cuenta de los márgenes negociadores. La última opción sería la salida

$13<\mathrm{http}$ //elsocialistadigital.es/europa/item/679-la-comision-europea-reconoce-queel-tratado-de-la-ue-no-prohibe-la-emision-de-deuda-publica-comunitaria.html>

${ }^{14}$ Die Zeit, 30.08.12. Declaraciones citadas también en La Vanguardia, 8.06.15 y El País, 20.08.13, en un artículo del propio Habermas titulado «Cuando las élites fracasan»: $<$ http://blogs.lavanguardia.com/diario-de-futuro/la-socialdemocracia-y-la-re-nacionalizacion-de-europa-habermas-irrumpe-en-las-elecciones-alemanas-76750 $>$ y $<$ http://elpais.com/elpais/2013/08/13/opinion/1376411438_682870.html> 
de la Unión, contemplada en el art. 50 del TUE, y que ahora el Reino Unido plantea seriamente.

Syriza enfocó su comienzo gubernamental, entre el segundo y el tercer rescate, como una negociación bilateral con la UE a todo o nada, y quizá no exploró de manera suficiente la vía del diálogo con gobiernos socialdemócratas más proclives a sus tesis. Aunque esta vía tampoco era clara. Francia e Italia, con gobiernos formalmente socialdemócratas, aplican políticas semejantes a las de la canciller Merkel, que las desarrolla en coalición con el SPD. Aunque parece que su posición se flexibilizó posteriormente, el vicecanciller alemán Sigmund Gabriel, a la sazón presidente del SPD, compartió la postura estricta expresada por sus socios democristianos con respecto a Grecia.

Según EuroActive ${ }^{15}$, en la actualidad hay ocho primeros ministros pertenecientes a la Alianza de Socialistas \& Demócratas, por siete liberales (ALDE) y seis democristianos (EPP). Sin embargo, si hacemos un repaso a algunos de esos gobiernos presididos por un socialdemócrata veremos que dicha variable no garantiza hoy en día un cambio cualitativo en la política económica de la UE.

Francia, con la aprobación de la Ley Macron ${ }^{16}$ de reformas liberales de la economía, no parece ser un socio fiable para Syriza. A ello hay que añadir que no está en condiciones de apoyar al nuevo gobierno griego en su intento de flexibilizar las condiciones del rescate, toda vez que a Francia se le ha perdonado el incumplimiento de los objetivos del Tratado de Estabilidad y se le ha concedido dos años más para conseguirlo.

Por su parte, Matteo Renzi, no parece estar en condiciones de plantear en Europa lo que no está haciendo en Italia, después de la aprobación de la Jobs $A c t$, que flexibiliza el mercado laboral, con una fuerte protesta sindical y con una escisión en la izquierda del Partido Democrático liderada por Stefano Fassina. Aun así, Renzi defiende públicamente una política distinta a la promovida por Alemania.

Es cierto que en Portugal se ha constituido un Gobierno de izquierdas entre el PS, el Bloco de Esquerda y el Partido Comunista. Pero no es menos cierto que el PSD (centroderecha, en la oposición) ha apoyado la polémica venta del banco público BANIF al Santander con un rescate estatal de 3.000 millones de euros, y que los aliados de izquierdas del PS han votado en contra. Asimismo, el Gobierno de Antonio Costa no acepta la aplicación de algunas medidas ordenadas por la Comisión para la aceptación final de su

${ }^{15}$ Disponible en <http://euroefe.euractiv.es/5943_infografias/3696910_que-partidopolitico-tiene-mas-lideres-en-las-cumbres-de-la-ue.html $>$

${ }_{16}$ Por Emmanuel Macron, ministro francés de Economía e Industria, impulsor de las reformas. 
presupuesto. Entre sus socios y la Comisión, Costa tendrá que hacer equilibrios para dar estabilidad a su Gobierno y a la economía portuguesa.

El Partido Socialdemócrata austriaco ha formado una Große Koalition o gran coalición con el democristiano ÖVP para frenar la subida del extremista FPO, mientras que los socialdemócratas suecos no han tenido más remedio que formar una coalición amplia con los verdes y el centro-derecha para aprobar sus presupuestos y evitar unas nuevas elecciones. A su vez, el progresista eslovaco Robert Fico ha formado otra coalición plural entre su partido, el socialdemócrata SMER, con el derechista Movimiento por una Eslovaquia Democrática de Vladimir Meciar y los nacionalistas húngaros de J. Slota, desarrollando una política igualmente liberal y poco generosa con los refugiados sirios.

Quizá la dirección de Syriza constató la insuficiencia de la socialdemocracia europea para intentar cambiar el sesgo liberal del Consejo. Aun así, se repitieron las elecciones y volvió a obtener la confianza de una parte importante del pueblo griego. Los electores helenos entendieron que la coalición de Tsipras era la única que podía sacarles del atolladero aunque fracasara en la primera negociación, toda vez que Nueva Democracia fue responsable de la situación y el PASOK y los demás partidos no estaban en condiciones de enderezar el rumbo.

Algo influiría en un cambio de política económica que en unas próximas elecciones al Parlamento Europeo se fraguara una mayoría electoral de izquierdas. Pero mientras aquélla resida en el Consejo, las elecciones nacionales seguirán siendo más importantes, puesto que será el color de los gobiernos que lo conformen el que determine si se mantienen como hasta ahora o experimentan algún cambio. Excepto en el caso de Grecia y España, no se vislumbra una alteración cualitativa en la correlación de fuerzas a nivel europeo hacia la izquierda, manteniéndose el bipartidismo clásico desde la Segunda Guerra mundial entre las fuerzas democristianas y socialdemócratas, sólo limitado por el ascenso, más que de las izquierdas transformadoras, de los nacionalismos de derecha (caso de Francia). Un hipotético éxito de Syriza en su negociación con el Eurogrupo habría estimulado el voto favorable a las posiciones más izquierdistas. Si además de Syriza, Podemos, Die Linke, Sinistra-Ecologia e Libertà y el Front de Gauche gobernaran en sus respectivos países, estaríamos ante un cambio cualitativo que se traduciría en una nueva mayoría en el Consejo, en la aplicación de otra política económica y en la reforma de los tratados. Pero esto no va a suceder, y la actual mayoría de gobiernos socialdemócratas no sugiere un cambio cualitativo a la vista de las políticas que están aplicando a nivel nacional ${ }^{17}$.

${ }^{17}$ En cambio, opinan lo contrario FERNÁNDEZ, J., La reorientación de Europa y las elecciones españolas (Cinco Días, 17.12.2015) y SÁnCHEZ CuencA, I., ¿Pactar qué? (in- 
A día de hoy, Syriza vuelve a gobernar pero habiendo pactado un programa de ajuste con Europa para evitar la salida griega del euro. El problema es que cada vez hay más sectores en Alemania y otros países del Norte que creen que ayudar a Grecia es ya inútil por desconfiar de sus posibilidades de crecimiento. Puede extenderse la idea de que las ayudas a Grecia sólo sirven para pagar deudas anteriores, no para regenerar su economía.

\section{LA TRANSFORMACIÓN DEL ESTADO-NACIÓN: ¿HAY OPCIÓN?}

El contexto europeo en el que ha actuado la socialdemocracia ha variado notablemente desde la posguerra mundial hasta ahora. Los años 50-70 se caracterizaron por la reconstrucción del continente como un espacio común de paz, seguridad y cooperación económica. Pero a la vez la de los Estadosnación sobre la base de la transformación de los anteriores Estados liberales en nuevos Estados del bienestar, que contemplaban no sólo los derechos individuales y de participación, sino también los sociales. Así, se consideró a los nuevos Estados europeos como suministradores principales de servicios públicos esenciales para la comunidad y se contempló una intervención relativa en la economía. El Estado pasó a ser no sólo una estructura política sino también un agente económico necesario, respetando el funcionamiento del mercado pero pudiendo regularlo en aras de la igualdad social.

Los nuevos Estados iban recuperando el peso industrial y primario que antaño tenía la minería y la siderometalurgia, desarrollando sectores como el automovilístico y otros que aparecieron entonces -electrodomésticos, plásticos-. Esta recuperación industrial permitía una cierta autosuficiencia económica y configurar nuevos Estados sociales y democráticos con bases fiscales propias. Los Estados, en una palabra, podían financiarse básicamente con los impuestos de unas poblaciones con altas tasas de actividad, y contaban con unas balanzas comerciales estables. Ese contexto fue el que marcó la acción de la socialdemocracia en favor del desarrollo de los nuevos Estados sociales y democráticos, con la aquiescencia de una democracia cristiana, inspirada en el pensamiento social de la Iglesia, que también ponía el equilibrio social por encima de los abusos del viejo capitalismo.

Sin embargo, dos hechos fundamentales cambiaron esta situación:

1. ${ }^{\circ}$ desde principios de los ochenta, los gobiernos de Reagan en EE.UU. y de Thatcher en Reino Unido modificaron las bases estructurales de las economías occidentales con su propuesta de «capitalismo popular». Fórmula que implicaba

foLibre, 30.12.2015). 
la privatización y la desregulación de la economía, así como la potenciación de la economía financiera y de servicios y el acceso de la clase trabajadora a la pequeña propiedad financiera, mediante la conversión de las empresas, privadas y públicas, en nuevas sociedades anónimas. Ello comportó un cambio económico y cultural, que afectaba a la estructura social por la importancia creciente del sector servicios, con una población activa cada vez más numerosa. El marco general, pues, era de aparición de nuevos sectores económicos y sociales, y del endeudamiento financiero tanto a nivel privado como público. Todo ello modificó el esquema socioeconómico propicio en el que actuaba la socialdemocracia, que vio cómo se desestructuraba su cuerpo electoral y las bases social, fiscal y económica del Estado. En adelante, los Estados ya no primarían sus ingresos en las políticas fiscal y comercial, sino que se irían endeudando y dependiendo cada vez más de la financiación exterior, tanto típica (organismos internacionales) como atípica (agentes del mercado).

2. ${ }^{\circ}$ La construcción europea, como se ha dicho, se realizó sobre las bases del mercado interior y la libre competencia, limitando la acción del Estado social que pudiera repercutir en el conjunto del continente. La supresión de las barreras comerciales y económicas que interferían en dicho mercado limitaban la acción de un Estado nacional que, en sentido contrario, se había desarrollado en un sentido más intervencionista, como se ha indicado en el anterior apartado. Así, se vivía un proceso con dos caras aparentemente contradictorias: nuevos Estados sociales e intervencionistas a nivel nacional, nueva Europa de mercado libre a nivel continental. Esta contradicción tendría que resolverse en algún momento en favor de una u otra orientación. Al avanzar el proceso de construcción europea, que acabaría imponiéndose, el principio del mercado libre se impuso sobre el de la intervención nacional. Sin duda, las políticas privatistas de Reagan-Thatcher y el avance de la globalización financiera contribuyeron definitivamente a incardinar la nueva Europa en ese contexto neoliberal.

Hay que decir que la socialdemocracia tuvo una mala experiencia con el Programa Común francés de socialistas y comunistas en 1982. La política de nacionalizaciones y de intervención estatal no dio los resultados esperados, sino una recesión económica a la que no querían llegar las nuevas socialdemocracias gobernantes de Grecia, España, y Portugal, entre otras. Asimismo, el colapso del régimen soviético y la caída del Muro de Berlín orientó a la socialdemocracia europea a postulados más permeables con el capitalismo de libre mercado, al que se veía como el único contexto posible y en el que, acaso, se podrían desarrollar determinadas políticas sociales para amortiguar sus perversos efectos.

A partir de ahí pareció como si la socialdemocracia se quedara sin modelo. Intentó reservar los servicios públicos elementales como sanidad, 
educación y pensiones, privatizando lo demás, renunciando a más intervencionismo del Estado, reduciendo la progresividad de la política fiscal, admitiendo como inexorables los efectos de la globalización y recurriendo a la financiación exterior del Estado. Todo lo más, se pasaba a defender el keynesianismo como propuesta de estímulo de la demanda interna mediante una política activa de inversiones en obras públicas. Pero aceptó los principios del mercado interior y del neoliberalismo. El marco jurídico descrito en el primer apartado de este trabajo fue pactado con la socialdemocracia, con gobiernos socialdemócratas en el Consejo. Todo el proceso europeo, los tratados constitutivos, los pactos de estabilidad de 1997 y 2012, todo ha sido pactado entre el centro-derecha y la socialdemocracia en el Consejo Europeo y en el Parlamento. Ha sido ese bipartidismo el que ha sostenido el proceso, y la socialdemocracia ha contribuido acríticamente.

Ahora, cuando se ven los efectos de esta evolución neoliberal y hay muestras de rechazo por una parte creciente de la ciudadanía europea, algunas voces de la socialdemocracia alzan su voz contra la política de austeridad defendida por Alemania y otros Estados (en España: Urquizu, 2012; Fernández, 2013; Blanco, 2014; López Garrido, 2014). Piden una nueva política económica europea y un nuevo marco institucional que la reconozca. Una nueva política económica que ponga el acento no en la reducción de déficit y del gasto público sino en el estímulo a la actividad económica en aras del crecimiento. $\mathrm{Y}$ un nuevo marco institucional que facilite una mejor gobernanza política y que se traduciría en:

- transformar la Comisión en un Gobierno europeo con poderes ejecutivos y hacerla responsable de la política económica, como lo son los gobiernos en los EE.MM.; en el Semestre Europeo, codecidir con el Consejo.

- ampliar las funciones legislativas del Parlamento Europeo y las competencias del BCE;

- dotar a la Comisión de la función de iniciativa legislativa para trasladar proyectos al PE;

- acelerar las uniones fiscal-laboral y social;

- animar la conversión de los partidos nacionales en partidos europeos.

Quizá sea demasiado tarde, porque ambas cosas, juntas, exigen una reforma de los tratados. De los mismos tratados que la socialdemocracia contribuyó a diseñar y aprobar, comenzando por Maastricht. Y exigen su renegociación con el mismo centroderecha con el que siempre se ha pactó porque se aceptaron sus postulados económicos. No parece que la socialdemocracia como movimiento europeo, ni los gobiernos socialdemócratas actuales, estén en condiciones de forzar esa renegociación, sino tan sólo de 
acompañar, con mejor o peor ánimo, los cambios institucionales que Alemania y sus Estados seguidores impulsen: acaso, la federalización de algunas políticas y de los mecanismos de decisión, pero en el Consejo, el Consejo Europeo y el Eurogrupo. Es decir, una mayor federalización económica, intergubernativa y cooperativa bajo la influencia de Alemania pero no una federalización orgánica depositada en las instituciones centrales de la Unión. Aunque el Semestre Europeo representa un avance, la Comisión y el Parlamento tienen un papel más propositivo que decisorio, reservado al Consejo y al Consejo Europeo.

Al ser una organización intergubernamental, la política de la UE no viene determinada por diferencias ideológicas o partidistas, como sucede en sus Estados miembros, sino por intereses territoriales de los gobiernos en el Consejo y por las relaciones interinstitucionales. El marco clásico derechaizquierda es más nacional que europeo, ya que las instituciones están compartidas por las diversas familias políticas a excepción del Parlamento. Se ha puesto de manifiesto en la elección de Jean-Claude Juncker como nuevo presidente de la Comisión: siendo el candidato del centro-derecha para las elecciones de 2014, se convirtió en el candidato del Parlamento frente a los que inicialmente prefería el Consejo Europeo, Christine Lagarde y Michel Barnier. Y, como tal, apoyado también por la socialdemocracia (excepto la española), a cambio de la introducción de nuevas medidas económicas de estímulo a la demanda, como el Plan de Inversión para Europa (conocido como Plan Juncker).

Al aceptar la construcción europea sobre la base del mercado interior libre, la socialdemocracia ha renunciado a dos mecanismos de intervención en la economía, que son el Estado nacional y un auténtico gobierno europeo. En cuanto al primero, las competencias monetaria o industrial eran determinantes para la autonomía económica. La fiscal la mantienen los Estados, pero con unas crecientes necesidades de financiación exterior. Realmente, las competencias actuales de los Estados son las derivadas de la aplicación del principio de subsidiariedad, por el que los Estados retienen las competencias no atribuidas a la Unión. Las más importantes en el terreno económico ya han sido atribuidas, y seguirán aumentando pero, como ya se ha indicado, en un proceso de federalización cooperativa en los órganos intergubernamentales, en los que la toma de decisiones estarán influidas por los intereses de los EE.MM. de mayor PIB. Aunque la Unión es susceptible de ir asumiendo mayores cotas de competencias implícitas, no parece tampoco que se avance en la gobernanza política, que es lo que ahora reclama la socialdemocracia. El paradigma dominante es, antes al contrario, estrechar la coordinación de las decisiones interestatales en materia económica, pero no crear nuevas instituciones centralizadas ni potenciar las ya existentes. Las reticencias de Alemania y de otros EEMM a la compra de deuda pública por parte del BCE 
y a la creación del MEDE -al que se impuso un régimen transitorio de aplicación- anuncian claramente cuál es su posición ante este proceso. Por lo tanto, los avances que haya en este sentido pueden ser limitados y no será fácil la atribución de nuevas competencias a la Unión. Y, si fuera así, se atribuirían básicamente al Consejo.

En este contexto, importantes sectores sociales reclaman más Estado, más accountability reconocible. En la medida en que la UE no la garantiza, lo que se pide es más Estado nacional, intentando recuperar algunas competencias sobre todo en materia económica y de intervención. Esta renacionalización la defienden tanto partidos de izquierda (Syriza, Podemos) como de derecha (Frente Nacional). También algunos sectores socialdemócratas creen que hay que recuperar el Estado y su potencial regulador (Blanco, 2014: 168-170). Pero, ¿cuál ha de ser su ámbito, nacional o continental? Es decir, ¿la disyuntiva es volver al Estado nacional, o avanzar hacia una mayor integración? Si aceptamos que volver al Estado nacional ya es imposible y además contraproducente (por los límites que implica en la políticas públicas), y si al mismo tiempo constatamos que avanzar hacia un Estado europeo es poco menos que una quimera (por las diferencias entre los Estados existentes y su negativa a desaparecer), ¿cuál es el camino?

Parece que la única respuesta realista es la de ir avanzando paso a paso, de acuerdo con la estrategia de Schumann-Monnet, en la integración material y competencial, procurando aclarar el marco institucional, de tal forma que los ámbitos decisorios fueran reconocibles por los ciudadanos. Un marco institucional que, tal como se apuntó antes, debería pasar por aumentar las funciones de la Comisión, el Parlamento y el BCE. Y profundizar en las políticas comunes, superando las contradicciones existentes en materias tales como inmigración, política exterior, asilo y refugio. Nos encontramos con el hecho de que los mismos Estados que piden políticas comunes en estas materias son renuentes a la cooperación y a ceder más competencias. La actual crisis de los refugiados es un claro ejemplo de ello. Incluso los EE.MM. han sido renuentes a la hora de aplicar las cláusulas de solidaridad contempladas en el 42.7 TUE y 222 TFUE solicitadas por Francia tras los atentados de noviembre en París. Bélgica, recientemente golpeada, ni siquiera las ha pedido.

La socialdemocracia debería reflexionar sobre la posibilidad de definir una política económica europea que fuera inspirada por la Comisión y ejecutada por los EEMM, pero no decidida por éstos. Hoy por hoy la función de iniciativa legislativa de la Comisión no se extiende a la política económica. En suma, alguna autoridad ha de haber en la Unión que sustituya a los Estados en su desarrollo. Si no es así, no ha de extrañar que haya partidos de izquierda que quieran recuperar un cierto intervencionismo estatal sobre el mercado aunque sea a nivel nacional. 


\section{ESCOLIO}

Europa está en una encrucijada, a medio camino entre los Estados nacionales y la unión política. Se vislumbra una Europa confederal, más que federal. Quizá el Estado transnacional en el que pensaba Ulrich Beck (1998). Pero incluso si nos paramos en la confederación podemos discutir sobre el nivel de integración al que se puede llegar. La confederación es un modelo que ya exige un cierto grado de federalismo. La duda es hasta qué punto y sobre qué órganos. Si, tal como se apuntó antes, potenciamos un federalismo intergubernamental o un federalismo central. Los Estados Miembros son conscientes de que se ha llegado a un punto en el que cualquier avance en la unión europea implica reducir sus competencias, y es lógico que sean prudentes. Por eso están conformes con que la integración se deposite en los órganos compuestos por ellos y en las materias consensuadas, aunque eso puede generar algunas contradicciones entre unos y otros. Se acepta una cierta federalización de la política económica, pero no en la PESC, inmigración, asilo y refugio. En este sentido, habrá que ver el destino de la reciente propuesta de una Agencia Europea para los Refugiados propuesta por la Comisión. Agencia a la que, para empezar, podría denominársele «Federal». ${ }^{18}$

Por otra parte, no es tan seguro que el papel de los Estados se reduzca con todo esto. Quizá la categoría histórica de «Estado-nación» haya desaparecido. Pero eso no significa que haya desaparecido el Estado como tal, sino que se ha transformado en un Estado miembro de la Unión, algo así como en un Estado confederado. Un Estado que, manteniendo su ámbito nacional, sin embargo ha perdido buena parte de su soberanía. Pero esto no significa que llegue a desaparecer. Sólo lo haría si la propia Europa se convirtiera en un gran Estado Federal, lo que exigiría un proceso constituyente que se intentó tímidamente en 2004 y no salió bien. Este proceso constituyente es difícil que lo volvamos a ver. Más bien avanzaremos, como ya se ha dicho, hacia una mayor federalización de algunas materias.

Pero, por paradójico que parezca, esta cesión de soberanía hacia la UE puede contribuir a la consolidación de los Estados pero con otro carácter. La obsesión por el control del déficit público, que es como decir de las cuentas públicas de todas las administraciones, le obliga a ser un órgano colaborador esencial para la UE, en detrimento de las administraciones internas subestatales, que verán, esas sí, claramente mermadas sus competencias. El caso de España es paradigmático por cuanto ambos procesos, cesión de soberanía hacia la Unión y mayor descentralización interna, parecen ser simultáneos. Pero en la práctica se puede apreciar cómo el proceso de control europeo se va imponiendo. Cuando la Generalitat de

${ }^{18}$ El Periódico, 6.04.16: <http://www.elperiodico.com/es/noticias/internacional/bruselas-sugiere-crear-una-agencia-europea-para-repartir-los-refugiados-5033209> 
Cataluña se queja de que cada vez está más controlada por el Gobierno central, es porque éste a su vez lo está por la Comisión. No es un control discrecional. En tiempos de crisis, los recursos disminuyen y los controles administrativos aumentan. Pero eso vale para todos, desde la Comisión hacia abajo. El esquema de control general que se vislumbra es el de Comisión-Estados, con lo que éstos fortalecen su papel de garantes del mismo de acuerdo con el principio de subsidiariedad, en detrimento sobre todo de sus administraciones inferiores, ya sean regionales o locales.

Esta evolución economicista no evitará los nacionalismos estatales. Sólo serán superables si se federaliza la Unión económica y políticamente, potenciando los órganos centrales y garantizando una gestión democrática y transparente de sus políticas.

\section{CONCLUSIONES}

- No sólo hay política económica EN la Unión Europea, sino que hay una política económica DE la Unión. Está definida en el artículo 119 del TFUE, y desarrollada en el conjunto de tratados y normas comunitarias. Los Estados son administraciones subalternas que, de acuerdo con el principio de subsidiariedad, aplican dicha política. Al estar más controlados por la UE -sobre todo por la Comisión y el Consejo- ellos a su vez controlan más a sus administraciones internas en el objetivo de controlar el déficit público, por lo que de rebote, y de acuerdo con el principio de subsidiariedad, su papel puede verse fortalecido a pesar de la cesión de soberanía hacia la Unión, en tanto que administraciones colaboradoras de ésta.

- El marco jurídico de la UE, con la cesión del ejercicio de competencias atribuidas por los Estados Miembros sobre todo en materia económica, no permite mantener la soberanía económica en manos de aquéllos. Cualquier partido, ante un acontecimiento electoral, debe tenerlo claro y no engañar a los electores con eso. Lo honesto, en caso contrario, es rechazar dicho marco y buscar la mayoría política necesaria para modificarlo.

- Dicha mayoría se ha de articular país por país, y no sólo en las elecciones al Parlamento Europeo, pues es en el Consejo donde se pueden arbitrar los cambios.

- La socialdemocracia no representa un cambio decidido en este sentido. Ha contribuido a la construcción de la actual Unión junto a liberales y democristianos. En la actualidad intenta presentar una opción a la política de austeridad proponiendo más el aumento de ingresos fiscales que el control excesivo del gasto para la reducción del déficit público. 


\section{BIBLIOGRAFÍA CITADA:}

BARÓn CRESPO, E., La era del federalismo (Barcelona: RBA, 2014).

BECK, U., ¿Qué es la globalización? (Barcelona: Paidós, 1998).

Blanco, F., La economía socialdemócrata. Crisis y globalización (Madrid: Tecnos, 2014).

EnZENSBerger, H. M., El gentil monstruo de Bruselas (Barcelona: Anagrama, 2014).

FERnÁNDEZ, J., Una alternativa progresista (Barcelona: Deusto, 2013).

Habermas, J., La constitución de Europa (Madrid: Trotta, 2012).

Held, D. y McGrew, A., Globalización/Antiglobalización. Sobre la reconstrucción del orden mundial (Barcelona: Paidós, 2003).

LóPez Garrido, D., La Edad de Hielo. Europa y Estados Unidos ante la Gran Crisis: el rescate del Estado del Bienestar (Barcelona: RBA, 2014).

Medina Ortega, M., El derecho de secesión en la Unión Europea (Madrid: Marcial Pons, 2014).

RUIPÉREZ, J., La «Constitución Europea» y la teoría del poder constituyente (Madrid: Biblioteca Nueva, 2000).

Rodríguez-Aguilera, C., El déficit democrático europeo (Madrid: Catarata, 2015).

TORREBlAnCA, J. I., ¿Quién gobierna en Europa? (Madrid: Catarata, 2014).

URQUIZU, I., La crisis de la socialdemocracia: ¿qué crisis? (Madrid: Catarata, 2012).

TITLE: The exercise of economic competences in the European Union: is possible another policy?

RESUMEN: La integración europea es difusa, combina los aspectos económico y politico y supone la atribución de parte de sus competencias por los Estados Miembros. El Estado-nación europeo de los años 50-70, más industrial y con suficiencia fiscal, fue un marco adecuado para el desarrollo de políticas socialdemócratas. Sin embargo, la globalización económica, las políticas neoliberales de Reagan y Thatcher a partir de los años 80, y una construcción europea consagrada al mercado interior, han transformado ese marco. Se analiza el marco jurídico que regula la política económica en la UE, y partiendo del mismo se plantea si hay una definición de la política económica y en qué principios se inspira. En caso afirmativo, se cuestiona si podemos hablar no sólo de política económica «en» la UE, sino también de una política económica «de» la UE. Si es así, quién la define y aplica, y si es posible el desarrollo de una política distinta. A partir del caso griego con Syriza, se plantea finalmente si dada la correlación de fuerzas en el Consejo y el Parlamento, y teniendo en cuenta los cambios de gobierno en algunos países del sur de Europa (Grecia, Portugal, ¿España?), puede haber un cambio de orientación al respecto.

ABSTRACT: European integration is diffuse, it combine economical and political aspects and means the assignment of part of her competences from the Member States. The european State-nation of 50's-70's years, 
more industrial and with fiscal sufficiency, was an appropriate framework for the development of social democrat policies. Nevertheless, economic globalization, Reagan and Thatcher's neoliberal policies parting from 80 's years, and a consecrated to domestic market european construction have transformed that framework. It's analized the legal framework that rules the economic policy in the EU, and parting from it arises if there is a definition of economic policy and which are its principles. In afirmative case, it's questioned if we can talk about not just an economic policy «in» $E U$, but about an economic policy "of» EU. If there is, who defines it and who implement it, and if is possible the development of a different policy. Parting from case of the Greece with Syriza, it arises finally if with the correlation of forces in European Council and Parliament, and attending the changes of government in countries of southern Europe (Greece, Portugal, Spain?), it could be a change of direction in this issue.

PALABRAS CLAVE: Integración, Europa, soberanía, política económica, subsidiariedad, federalismo.

KEY WORDS: Integration, Europe, sovereignty, economic policy, subsidiarity, federalism.

RECIBIDO: 23.05.2016

ACEPTADO: 19.12 .2016 